\title{
EXPERIMENTAL ANALYSIS OF THE ETCHING PROCESS FOR VALIDATION OF NON- CONVENTIONAL SLOT MACHINING IN AERO ENGINE COMPONENT MANUFACTURING
}

\author{
C. Baier ${ }^{1 *}$, M. Weigold ${ }^{2}$ \\ ${ }^{1}$ Rolls-Royce Deutschland Ltd. \& Co. KG, Hohemarkstraße 60-70, 61440 Oberursel, Germany \\ 2 Technical University of Darmstadt, Institute for Production Management, Technology and Machine Tools (PTW), \\ Otto-Berndt-Straße 2, 64287 Darmstadt, Germany \\ * C. Baier; e-mail: Carolin.Baier@Rolls-Royce.com
}

\begin{abstract}
To fulfill service life and integrity requirements when using a non-conventional process in aerospace industry, a comprehensive validation needs to be carried out. According to the state of the art, the characteristically resulting recast layer of wire electrical discharge machining (WEDM) can be reduced to a few microns. To meet existing requirements for eliminating the recast layer, it is essential for validation to consider the complete process chain consisting of WEDM and the subsequent processes. In this paper, the subsequent process etching in series production is investigated with regard to its suitability for the removal of the white brittle surface layer without leaving any residues. By using a Design of Experiment approach, the residue-free removal of the recast layer by electrolytic etching is investigated.
\end{abstract}

\section{Keywords:}

Wire EDM; Turbine Discs; Nickel-Based Alloys; Electrolytical Etching

\section{INTRODUCTION}

As aviation has become an increasingly important part of today's global interacting society, whether for passenger or freight transport, it is becoming more and more important to pursue climate goals in the aviation industry as well. For this reason, efforts are being made to develop constantly more climate- and environmentally friendly engines. To design an engine efficiently, the bypass ratio will be increased and with this the core engine will be decreased. The efficiency of the core engine is related to the compressor head and the turbine entry temperature. For this reason, the increase of efficiency of an engine is linked to a rise in temperature and rotational speed [Koppe 2012]. In order to remain costefficient and not significantly reduce the service life of an engine, new materials are constantly being tested. These include titanium, nickel-based alloys and powder metallurgy materials [Braeunling 2004]. However, these hightemperature resistant materials are difficult to machine. To be able to implement and machine these materials, new manufacturing processes are constantly being investigated for their use in aviation. A new manufacturing method must be extensively tested and then comprehensively validated under aerospace-critical aspects.

The state of the art in manufacturing profile slots in turbine discs is currently the broaching manufacturing process [Seimann 2018]. On the one hand this process is characterized not only by the high surface qualities and accuracies that can be achieved, but also by its high productivity [Klocke 2018] [Denkena 2011] [Ortiz-de-Zarate 2018]. On the other hand, broaching is characterized by a cost- and time-intensive tool production. The time factor also tends to be disadvantageous in the case of geometry changes. [Klocke 2014] Especially in new product introduction projects the flexibility of the process is more important than the productivity. However, since it is more and more important to be able to react quickly to different conditions, the non-conventional manufacturing process of wire electrical discharge machining (WEDM) is to be validated for its application in the aviation industry. This is a highly flexible process in which material properties such as hardness or ductility are of secondary importance. Only the conductivity of the material to be machined must be given in order to be able to use WEDM. [Bergs 2018] [Klocke 2018] Since profile slots in high pressure turbine discs are among the most critical and life-limiting features of an engine, a comprehensive validation strategy must be developed and implemented here. Such a possible strategy was presented in [Baier 2021]. Validation must not only consider the manufacturing process itself, but also other process steps in the overall manufacturing method.

Since the application of the WEDM process produces a typical brittle white surface layer, the so-called recast layer, which is seen as area of potential crack initiation and is therefore undesirable, the following section investigates whether and how this layer can be removed. For this reason, electrolytic etching, which is a required standard within the manufacturing route of critical parts, will be 
analyzed for its ability to remove the recast layer completely.

\section{ELECTROLYTICAL ETCHING}

Components in the aviation industry are subjected to regular inspections at various stages within the manufacturing route. To ensure that no manufacturing anomalies are present, all critical parts are visually inspected for surface anomalies and cracks after machining. In these processes, the engine components are checked for cracks in different ways to locate irregularities on the surface. In order to prepare the surface of the components for these inspections, they are etched. In Figure 1 a part could be seen before etching on the lefthand side and on the right-hand side in etched condition.

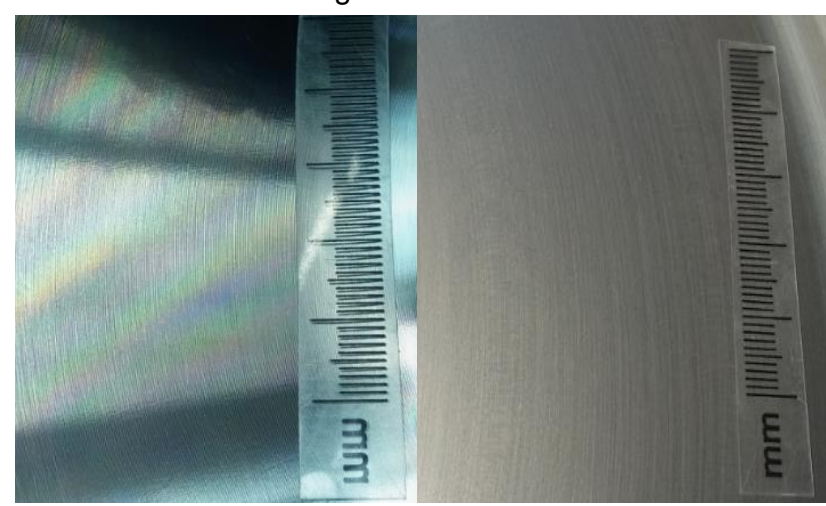

Figure 1: Surface before (left side) and after (right side) etching process

Since etching is an inevitable part of the manufacturing method to achieve different grey levels for inspection preparation, this could be adapted to remove material in a micrometer range, means to the use of the WEDM. The amount of removed material and the expected present recast layer thickness are in a comparable range. Therefore, it is seen likely that the whole impacted subsurface area by WEDM is removed within standard manufacturing process chain by etching, if the right set of parameters is applied. The electrochemical removal is also intended to eliminate the heat-affected edge layer that has been thermally damaged by electrical discharge machining and thus increase the dynamic strength of the part. Another advantage of etching the brittle white surface layer without leaving residues is, that after the process step the component surfaces are no longer subjected to tensile residual stresses. [Klocke 2007]

To use the etching process for eliminating the recast layer, the electrolytic removal process needs to be understood first. For this reason, the procedure will be presented in the following. During etching, the components are plunged into an electrolyte medium and an applied DC voltage forces electrolysis to take place, which produces the necessary material removal for the subsequent testing processes. Figure 2 schematically illustrates the dip etching process.

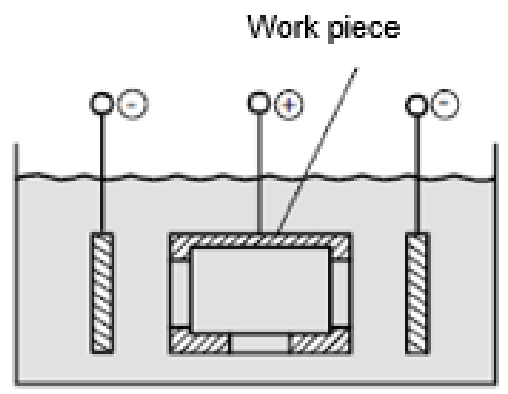

Figure 2: Electrochemical Removal [Klocke 2007]

During the electrolytic etching process, the current flow occurs due to potential differences in the micro range, which are caused, for example, by dislocations at the grain boundaries or defects in the material. As a result, the removal on the surface is irregularly distributed. [Klocke 2007]

Since residues of cooling lubricants and other materials used, are present on the surface due to various mechanical processing steps and can thus influence the etching process, the turbine discs are cleaned prior to etching. After the etching process, insoluble oxide residues adhere to the component, which must be removed for successful component and recast layer removal testing. The residues are removed chemically by decapitation in hydrofluoric and nitric acid. Figure 3 schematically illustrates the process flow of the etching process.

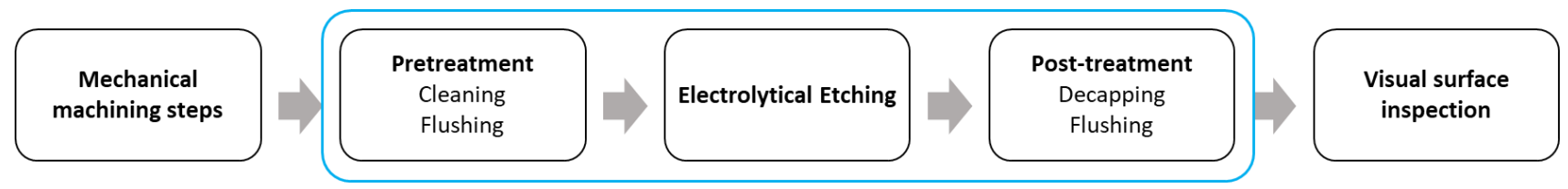

Figure 3: Process cycle of electrolytic etching

\subsection{Faraday Law}

Faraday's law is representing the theoretical basis for all parameters, which were chosen in the applied etching process. Faraday's law in equation (1) indicates that for the deposition of a quantity of material $n$ of an ion of valence $z$, a charge $Q$ is required. [Kurzweil 2007]

$Q=Z * F * n$

$F$ describes the Faraday constant, which is the charge, that is required to deposit one mole of a monovalent ion. The necessary deposition of the mass $m=M^{*} n$ of a substance with the molar mass $M$ is therefore [Kurzweil 2007]:
$Q=\frac{F * Z * m}{M}$

The material removal at the anode can now be described by Faraday's law and, with known current / and electrolysis/ etching time $t$, can be formulated via the relationship between charge, time and current $Q=I^{*} t$ as in equation (3) [Klocke 2007]:

$m=\frac{M}{z * F} * I * t$ 


\subsection{Process noise}

Faraday's law forms the theoretical basis of the removal process. However, in practice, other general conditions are given. In order to pay attention to these influences, these factors will be discussed in the following.

It is not only residues from previous processing steps of the turbine discs that have an influence on electrolytic etching. Rather, there are a large number of process noises during the process. This includes the system setup with the electrodes, the contacting and also the fixture of the object to be etched as well as the pretreatment of the component, during which contamination of the surface can also occur. Furthermore, the etching bath concentration is a factor, influencing the etch removal and therefore directly the etching result. Furthermore, the component itself with its geometric complexity, the volume, the surface and the material must not be disregarded. Based on a Failure Mode and Effects Analysis (FMEA), four factors could be identified as primary influencing factors. On the one hand, the bath temperature is important. According to [Klocke 2007], the removal rate increases with increasing bath temperature. Again, the environmental temperature and also the circulation in the bath have an influence on this. Another important process variable is the etching time. According to Faraday, the etching time is proportionally related to the etch removal rate. Another influencing variable is the component position in the etching bath, which could be detected in preliminary investigations by Rolls-Royce Germany. Possible reasons for this can be both, local changes in the flow, which affects ion transport, and an influence of local concentrations and temperatures as well as the electric field. Finally, the current density has an influence on the etch removal. This can be adjusted by changing the voltage applied between the electrodes and the workpiece.

\section{EXPERIMENTAL INVESTIGATION RESULTS}

AND

In order to demonstrate the previously presented theoretical principles in practice and to prove the realistic process conditions to remove the recast layer completely, experiments were carried out on a DoE (Design of Experiment) basis.

\subsection{Design of Experiment}

One of the main strengths of statistical experimental design is efficiency. In order to be able to illustrate this, in practice experimental designs are very often used to investigate a large number of factors and thereby provide reliable results. At the one factor at a time model only one parameter is changing during the experiments. For this reason, interactions between influencing factors may not be detected and considered while using this approach. In contrast, with a DoE approach several factors are varied. Since a full factorial experimental design is no longer feasible with a large number of influencing factors, a screening (also called partial or sub-factorial experimental design) is often used to achieve a maximum meaningful result with a minimum loss of information and as few trials as possible. This could be reached by building an alias structure. This means, that some interactions between the factors could be replaced by another factor. While doing this, the number of factors increases from $k=4$ to $k=5$ and the number of replaced interactions to $p=1$. This results in a new sub-factorial experimental design of the form $2^{5-1}$. [Siebertz 2017] [Linss 2018]

A screening design was also carried out in this case. Here, the previously determined primary influencing parameters were selected to determine the effects. These four parameters were varied between minimum and maximum values which were established by preliminary tests.

Tab. 1: Chosen factors with minimum and maximum values

\begin{tabular}{|l|c|c|}
\hline Factor & Minimum & Maximum \\
\hline Temperature & $10^{\circ} \mathrm{C}$ & $20^{\circ} \mathrm{C}$ \\
\hline Voltage & $5 \mathrm{~V}$ & $6 \mathrm{~V}$ \\
\hline Position & Outer position & Central position \\
\hline Etching time & $120 \mathrm{~s}$ & $240 \mathrm{~s}$ \\
\hline
\end{tabular}

The temperature was varied between $10{ }^{\circ} \mathrm{C}$ and $20^{\circ} \mathrm{C}$, following process instructions from common practice. The preliminary tests showed an insufficient etching effect at a voltage of up to $4 \mathrm{~V}$ and initial over etching in some areas of the specimen at $7 \mathrm{~V}$ and above. For this reason, the minimum was set to $5 \mathrm{~V}$ and the maximum to $6 \mathrm{~V}$. Since the position of the component in the etching bath also has an influence on the local etch removal and the fixture used offers the possibility of varying the position parallel to the electrodes, the component position was also considered in the experimental design by applying screenings. Two outer and one central position were selected to change these. Furthermore, the etching time was considered as a factor in the experimental design. The setting of this results from preliminary tests and an estimation using Faraday's law. A maximum etch removal of $10 \mu \mathrm{m}$ was assumed, since the recast layer to be removed will not exceed $10 \mu \mathrm{m}$ according to the current state of the art. The etching time is limited at the bottom by the rise time required when setting the voltage. This results in a maximum of $240 \mathrm{~s}$ and a minimum of $120 \mathrm{~s}$.

During the experiments the removal of material as target value was calculated via weight measuring of the specimens before and after the etching process. Using Faraday's law, the removal value from the weight measurement could be converted into $\mu \mathrm{m}$.

\subsection{Experimental setup}

A custom-built fully automatic platform was used for the experimental investigations. Figure 4 shows the etching bath with the contacting (1), the electrodes (2) and the inflow (3). Since this is a fully automatic platform, various control and monitoring mechanisms were also used here. In the etching bath, the temperature of the bath, the voltage applied during the etching process, the current and also the density of the bath are monitored.

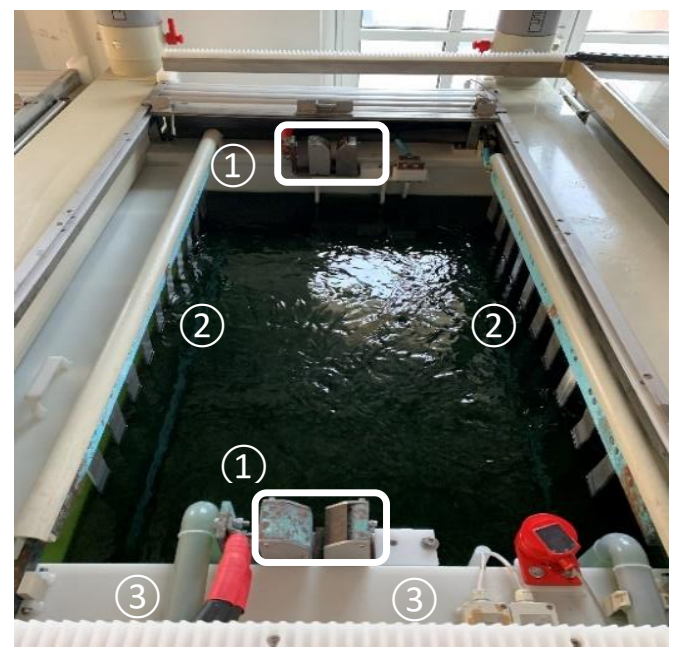

Figure 4: Etching bath 
Figure 5 shows the fixture that was used for the experiments. Here the numbering 1 to 6 of the different possible positions can be seen.

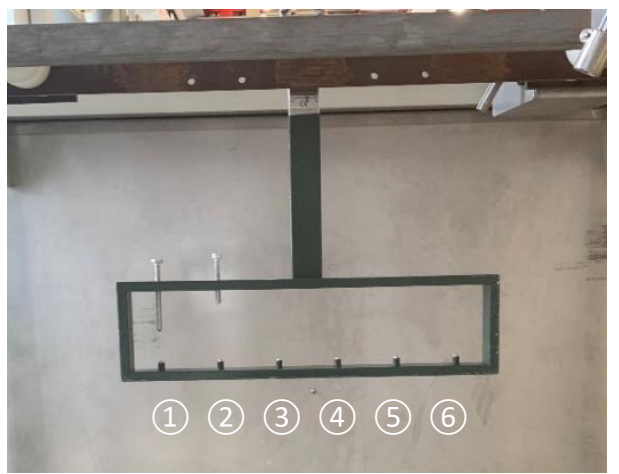

Figure 5: Etching fixture with position 1 until position 6

\subsection{Work piece material}

The work piece material used is Allvac 718 Plus $^{\circledR}$. This material is representing a nickel-based alloy, which is used in aero engine manufacturing. The following Table 2 shows the chemical composition of this alloy. Allvac 718Plus ${ }^{\circledR}$ is a further development of Inconel 718 to improve the good properties in processing the super alloy with the thermal stability and high continuous operating temperature of Waspaloy [Springmann 2015].

Tab. 2: Chemical composition of Allvac 718Plus ${ }^{\circledR}$. [Springmann 2015]

\begin{tabular}{|c|c|c|c|c|c|c|c|c|c|c|c|c|}
\hline \multirow{2}{*}{ Material } & \multicolumn{12}{|c|}{ Chemical composition in percent by weight } \\
\hline & $\mathrm{Ni}$ & $\mathrm{Cr}$ & $\mathrm{Fe}$ & Co & $\mathrm{Nb}$ & Mo & W & Al & $\mathrm{Ti}$ & C & $\mathrm{P}$ & B \\
\hline $\begin{array}{l}\text { Allvac } \\
\text { 718Plus }\end{array}$ & Rest & 18 & 10 & 9 & 5,45 & 2,8 & 1 & 1,45 & 0,7 & 0,025 & 0,014 & 0,006 \\
\hline
\end{tabular}

\subsection{Specimen}

The specimens used, made of the aerospace-typical material Allvac 718Plus, were taken from a serial production grade material. This ensures that the specimens behave in the same way as aerospace components. The specimens were cut from the turbine disc using WEDM. A simple rectangular geometry of the specimens was favored in order to be able to focus the analysis entirely on the factors influencing the electrolytic etching process. After extraction, the samples were examined under the scanning electron microscope (SEM), revealing the fractured surface characteristic of WEDM. It is shown in Figure 6.

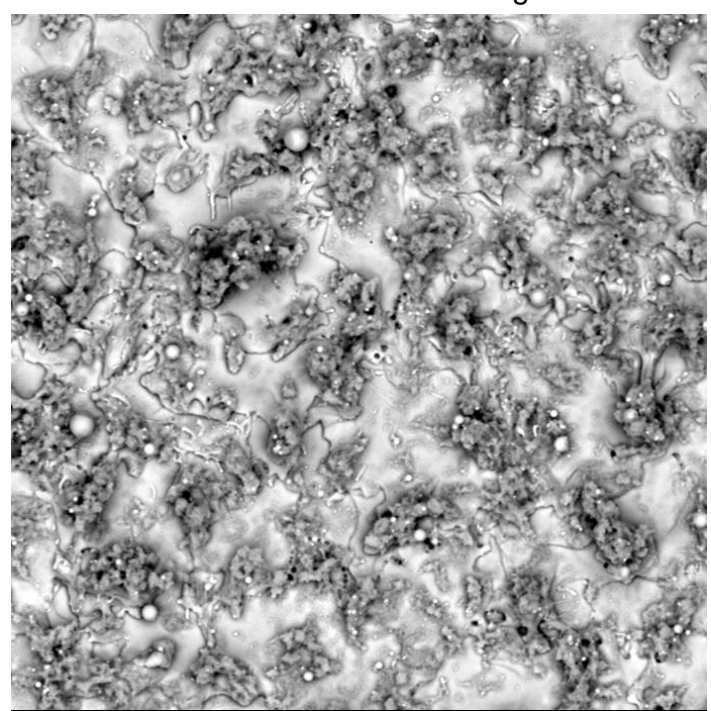

Figure 6: Microscope image of the surface after WEDM processing

In Figure 6 it is recognizable that the surface was molten during the WEDM process. The dark areas of the surface indicate oxide residues. To investigate the specimen surface with its recast layer and residues in detail an EDX analysis was carried out.

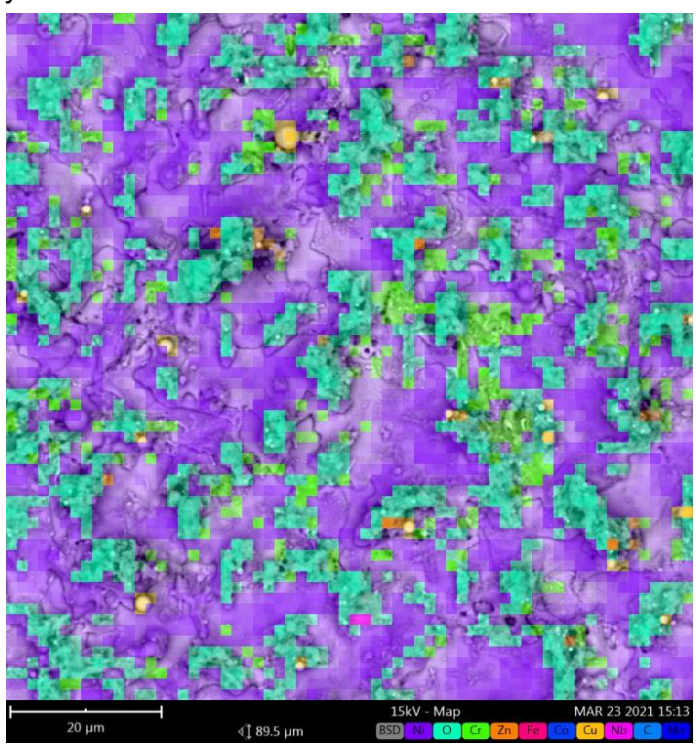

Figure 7: Energy dispersive X-ray spectroscopy (EDX analysis) of the WEDM surface

Figure 7 shows the typical residues on the surface after WEDM machining, which were determined by energy dispersive X-ray spectroscopy (EDX analysis). It can be seen that various deposits are present on the nickel-based alloy. Of significance are wire residues, which make up the copper and zinc content, and oxide residues from the WEDM machining. Furthermore, chromium deposits can be found on the surface, which are, however, an integral part of the alloy.

\subsection{Results}

As already described, the tests were carried out according to the designed screening test plan according to DoE. Here, 
the etch removal was determined for each sample by weighing before and after etching. With the support of the software used, a Pareto Chart could be created, in which the four main factors influencing etch removal, presented previously, are shown. Figure 8 shows, that etching time has the most significant effect on etch removal. Thus, the etching time offers an effective adjustment mechanism to vary and adapt the process. However, it is important not to vary the etching time too much, as this can lead to local over etching. Furthermore, the bath temperature also has an important influence on the etch removal. For this reason, a cooling unit on the etch bath must control the temperature during the process to avoid unwanted effects. According to the Pareto Chart, the voltage and position of the component in their selected limits do not provide much leverage to essentially influence the etching result with respect to the amount of etch removal.

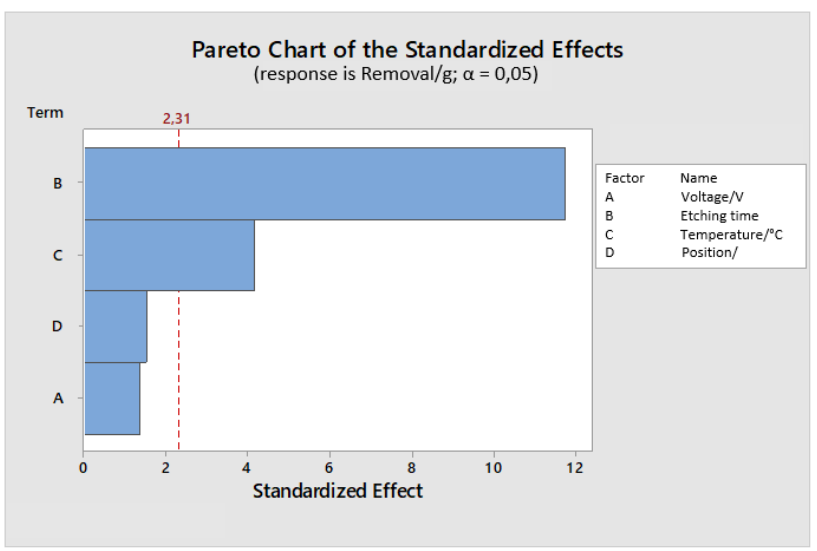

Figure 8: Pareto Chart of the standardized effects

With these results from the DoE, further samples were etched. A maximum recast layer thickness of $10 \mu \mathrm{m}$ was assumed, since it can be assumed that according to the current state of the art in the WEDM process, the recast layer only has a maximum thickness of up to $6 \mu \mathrm{m}$ or less [Baier 2021] [Welling 2015]. To check whether the recast layer on the surface of the samples could be removed completely by electrolytic etching, EDX analysis was also performed on the samples after the etching process. Figure 9 shows the surface of the etched samples. Here it is clearly visible, that all wire residues on the surface could be removed. Only inclusions of components of the material, such as Iron, Niobium or Molybdenum, could be made visible in the surface analysis. It can therefore be assumed, that the recast layer has been completely removed with the selected parameters.

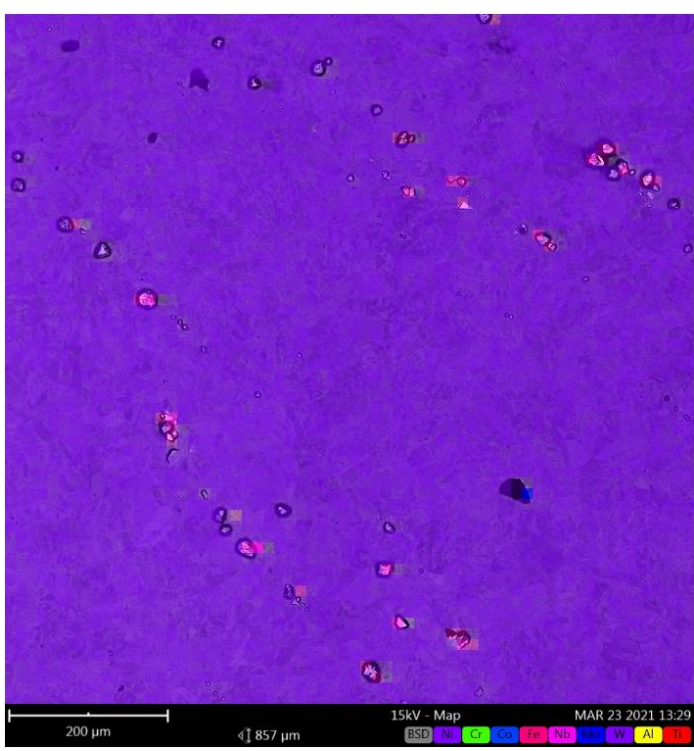

Figure 9: Energy dispersive $X$-ray spectroscopy (EDX analysis) of the WEDM surface after etching using optimized parameters

\section{SUMMARY AND CONCLUSION}

The objective of the conducted research work was to be able to set the influencing variables on the electrolytic etching process in such a way, that residue-free removal of the recast layer after WEDM processing is possible.

In the previous chapters, the electrolytic etching process was introduced, analyzed and main factors influencing it were elaborated, which were then prioritized using a statistical experimental design, based on their effects on the result. Subsequently, these findings have been successfully verified on samples where the recast layer could be removed completely using the chosen parameters. After the development of the presented correlations and the successful verification of the results on samples of simple geometry, it will be possible in the future to transfer these assumptions and investigation results to complex geometries, such as profile slots on turbine discs.

\section{ACKNOWLEDGEMENT}

The financial support of these investigations by the German Federal Ministry of Economy and Energy (BMWi) in the frame of the LUFO V RoK-Inn programme - 20T1715 is gratefully acknowledged.

\section{REFERENCES}

\section{Paper in a journal:}

[Baier 2021] Baier, C., Weigold, M.: Industrielle Akzeptanz alternativer Verfahren. Werkstattstechnik, February 2021, 1/2 2021, 12-17.

\section{Paper in proceedings:}

[Bergs 2018] Bergs, T., et al.: Surface integrity and economical assessment of alternative manufactured profiled grooves in a nickel-based alloy. $18^{\text {th }}$ Machining Innovations Conference for Aerospace Industry, MIC18, 2018: Procedia Manufacturing 18, 112-119

[Klocke 2014] Klocke, F., et al.: Evaluation of Advanced Wire-EDM Capabilities for the Manufacture of Fir Tree Slots in Inconel 718. $6^{\text {th }}$ CIRP International Conference on High Performance Cutting, HPC2014, 2014: Procedia CIRP14, 430-435 
[Ortiz-de-Zarate 2018] Ortiz-de-Zarate, G., et al.: Experimental and FEM analysis of surface integrity when broaching Ti64. $4^{\text {th }}$ CIRP Conference of Surface Integrity, CSI 2018, 2018: Procedia CIRP 71, 466 - 471.

[Seimann 2018] Seimann, M., et al.: Multi Flank Chip Formation in Fir-Tree Broaching Inconel 718 with Cemented Carbide. 46th SME North American Manufacturing Research Conference, NAMRC 46, Texas, USA, 2018: Procedia Manufacturing 26, 503-508

[Springmann 2015] Springmann, M., et al.: Application of Fracture Mechanics for the Life Prediction of Critical Rotating Parts for Aero Engines. Recent Trends in Fracture and Damage Mechanics. Heidelberg: Springer, 87-101, ISBN 978-3-319-21467-2

\section{Books, Technical reports or thesis:}

[Braeunling 2004] Braeunling, W. Flugzeugtriebwerke. Grundlagen, Aero-Thermodynamik, Kreisprozesse, Thermische Turbomaschinen, Komponenten und Emissionen. ISBN: 3540405895. Berlin Heidelberg: Springer, 2004.

[Denkena 2011] Denkena, B., Tönshoff, H.: Spanen Grundlagen. Heidelberg: Springer, 2011. ISBN 978-3-64219771-0
[Klocke 2007] Klocke, F., Koenig, W.: Fertigungsverfahren 3. Abtragen, Generieren und Lasermaterialbearbeitung. Berlin: Springer, 2007. ISBN 10 3-540-23492-6

[Klocke 2018] Klocke, F.: Fertigungsverfahren 1. Zerspanung mit geometrisch bestimmter Schneide. 9. Edition, Berlin: Springer Vieweg, 2018. ISBN 978-3-66254206-4

[Koppe 2012] Koppe, M. Kraftstoffverbräuche in Turbofan, Propfan und Turboprop im Vergleich. Hamburg, Online Source, $\quad$ http://www.fzt.hawhamburg.de/pers/Scholz/arbeiten/TextKoppe.pdf, 2012 (accessed 23.02.2019).

[Kurzweil 2007] Kurzweil, P., et al. Physik Formelsammlung. Wiesbaden: Vieweg+Teubner, 2007. ISBN 978-3-8348-0251-4

[Linss 2018] Linss, G.: Qualitaetsmanagement fuer Ingenieure. Muenschen: Hanser, 2018. ISBN 978-3-44643936-8

[Siebertz 2017] Siebertz, K., et al. Statistische Versuchsplanung. 2. Edition, Berlin: Springer Vieweg, 2017. ISBN 978-3-662-55742-6

[Welling 2015] Welling, D.: Wire EDM for the Manufacture of Fir Tree Slots in Nickel-Based Alloys for Jet Engine Components. Aachen: Apprimus, 2015. ISBN 978-386359-361-2 